\title{
River flow response to changes in vegetation cover in a South African fynbos catchment
}

\author{
Allen Hope ${ }^{1 *}$, Anders Burvall ${ }^{2}$, Talita Germishuyse ${ }^{3}$ and Terrence Newby ${ }^{3}$ \\ ${ }^{1}$ Department of Geography, San Diego State University, 5500 Campanile Drive, San Diego, CA 92182-4493, USA \\ ${ }^{2}$ HDR Inc., 8690 Balboa Avenue, Suite 220, San Diego, CA 92123, USA. \\ ${ }^{3}$ Agricultural Research Council - Institute for Soil, Climate and Water, Pvt. Bag X79, Pretoria 0001, South Africa
}

\begin{abstract}
Mountain fynbos catchments in the Western Cape region of South Africa are prone to substantial changes in land cover due to invasion by exotic tree species (and their clearing), fires, and vegetation response to inter-annual variations in rainfall. While small catchment experiments and modelling studies have pointed to reductions in river flow as catchment biomass increases, there is little empirical evidence of land cover change affecting river flow in large catchments that are important sources of water for the region. Monitoring changes in above-ground green biomass in multiple large catchments is challenging, but may be accomplished using a remotely sensed spectral vegetation index. It was hypothesised in this study that annual river yield (river flow as a fraction of rainfall) in the Molenaars catchment near Paarl, South Africa co-varies with an index of green vegetation cover derived from satellite data (the normalised difference vegetation index, NDVI). The catchment was partitioned into 'upland' and 'lowland' zones and the relationship between annual river yield and summer NDVI was determined for each zone over an 18-year period. There was a statistically significant negative linear relationship between annual river yield and the NDVI of the lowland zone when three outliers were excluded from the analysis. These outliers corresponded to periods with prolonged drought conditions when river yield appeared to be decoupled from vegetation water use in the lowland zone. There was no relationship between river yield and changes in the NDVI in the upland zone where plants were unlikely to have sustained access to adequate soil water for transpiration. The importance of considering the location of land cover changes in a catchment, and inadequacies in high-elevation measurements of rainfall in this mountainous region, were highlighted in the study.
\end{abstract}

Keywords: remote sensing, normalised difference vegetation index, Molenaars River, invasive vegetation, DWAF Working for Water Programme, mountain catchments

\section{Introduction}

Mountain catchments in the Western Cape Province of South Africa are important sources of water for the region, including the Cape Town metropolitan area. Fynbos vegetation covers many of these catchments, resulting in landscapes that are susceptible to frequent fires and invasion by exotic woody species. These woody species tend to be taller in stature than the native fynbos shrubs, causing an increase in above-ground biomass. Replacement of native fynbos by invasive species has been associated with reductions in river flow due to increased transpiration rates (Scott, 1999; Le Maitre et al., 2000; Dye et al., 2001). Estimates of river flow reductions have generally been made using empirical relationships between catchment biomass and flow reductions (e.g., Le Maitre et al., 2000), small catchment experiments where the fynbos shrubs have been replaced by tree plantations (e.g., Scott 1999), and measurements of river flow or evapotranspiration over short periods following the removal of invasive vegetation in specific locations (e.g. Dye and Poulter, 1995).

Little is known about the river flow response of large catchments to changes in above-ground biomass associated with invasion by exotic woody species or their clearing. Large catchments

\footnotetext{
* To whom all correspondence should be addressed.

용 +1 619 594-2777; fax: +1 619 594-4938; e-mail: Hope1@mail.sdsu.edu

Received 23 July 2008; accepted in revised form 10 November 2008.
}

may have significant non-uniform spatial variations in land cover, soils, fire history, and rainfall. Siriwardena et al. (2006) suggest that these heterogeneities are major factors contributing to the inconsistent response of different size catchments to changes in forest cover.

Attempts to relate river flow response to variations in vegetation cover in large fynbos catchments (area $>100 \mathrm{~km}^{2}$ ) are complicated by a number of factors. The spread of invasive species is a gradual and a spatially variable process that is difficult to monitor and quantify over large areas. Clearing invasives as part of catchment management plans, such as the South African Department of Water Affairs and Forestry (DWAF) Working for Water Programme (http://www.dwaf.gov.za/wfwh), may take many years and include follow-up clearing. Data quantifying changes in vegetation due to clearing are not always readily available in a timely manner, and there are no established and tested procedures for translating the documented clearing data (e.g., area and density of cleared vegetation) into variables that can be used to estimate changes in hydrological fluxes.

Like most Mediterranean-type ecosystems (MTEs), fynbos landscapes are prone to frequent fires. These episodic events dramatically modify land cover for many years and any single event may only affect parts of a large catchment. Consequently, these landscapes tend to be a patch-work of stands in various stages of post-fire recovery with different transpirational capacities due to variations in leaf area index (LAI) and rooting depth. This fire-driven heterogeneity in catchment vegetation cover compounds the challenge of assessing the impact of invasive 
vegetation on river yield. Furthermore, experiments designed to determine how catchment water yield is affected by burning fynbos vegetation have produced contradictory results (Bosch et al., 1986).

It is a formidable task to quantify vegetation spatio-temporal dynamics in large fynbos catchments or in multiple catchments across the Western Cape region. Vegetation cover needs to be expressed in quantities that describe the water transfer capacity of vegetation in the soil-plant-atmosphere system. Aboveground variables that satisfy this requirement are LAI, transpirationally active (green) biomass and canopy conductance. Spectral vegetation indices based on red and near infrared reflectance data collected from satellite or aircraft platforms covary with these biophysical quantities (Sellers, 1985). Because of these relationships, vegetation indices have shown promise for estimating catchment-scale actual evapotranspiration (Szilagyi, 2000). Although spectral vegetation indices relate directly to the above-ground vegetation characteristics, they may also provide an indirect measure of vegetation access to soil water given the relationship between plant canopy stature and rooting depth

Modelling studies and small catchment experiments are valuable for establishing the possible response of large catchments to changes in vegetation. While it is important to evaluate model predictions using observed variations in land cover and river flow in large catchments, there are significant challenges associated with these empirical studies in the Western Cape region. Estimating rainfall in mountainous catchments is prone to large errors since most of the rain gauges tend to be at low elevations, and the generally larger contribution at high elevations is under-sampled or not sampled. Tracking vegetation cover using satellite data may also be subject to significant uncertainties due to frequent cloud cover and shadows from mountains. Since changes in land cover may only impact a small fraction of the catchment area, the effect on river flow may be small relative to the errors in rainfall and river flow measurements.

\section{Research objectives}

Given the complex spatial and temporal dynamics of vegetation in large fynbos catchments, including changes associated with exotic invasions/clearing and fires, it is necessary to consider the overall changes in vegetation condition that may affect river yield. Consequently, no distinction was made in this study between the cause of inter-annual variations in vegetation state (growth of invasives, clearing, fires, drought/water stress) and their individual contributions to any change in river flow. The goal of the study was to test the general hypothesis that annual river yield (river flow as a fraction of rainfall) co-varies with the amount of transpirationally active (green) vegetation in a catchment which is quantified using a spectral vegetation index. The hypothesis was tested using data from the Molenaars catchment near Paarl, South Africa $\left(\operatorname{area}=113 \mathrm{~km}^{2}\right)$. This catchment is representative of mountain fynbos catchments in the Western Cape region that have been invaded by exotic tree species and subject to clearing as part of the Working for Water Programme.

The research hypothesis presented above is consistent with the conceptual basis of a method used by Le Maitre et al. (1996) and Van Wilgen et al. (1997) to estimate river flow reductions in fynbos catchments. While these authors used total above-ground biomass in a linear regression model to estimate river flow reductions, spectral vegetation indices respond primarily to transpirationally active biomass which could be expected to be a better indicator of variations in transpiration losses in a catchment

Upland and lowland zones may play contrasting roles in the water balance of mountainous catchments. Since rainfall generally increases with elevation, the upland zones tend to be important water producing areas while lowland zones may be responsible for a disproportionate fraction of evaporative losses. Lowland zones are often characterised by deeper soils, greater soil water availability for plants and more vegetation growth, factors that promote transpirational losses. Consequently, it is important to distinguish between land cover changes in lowland and upland landscapes when assessing the effects of these changes on catchment hydrological processes (Huxman et al., 2005). This distinction was also recognised by Le Maitre et al. (2000) in a modelling study to predict the impact of invasive tree species on river flows in the Western Cape region. The distinction is related largely to the differences in general availability of water in the root zone (Le Maitre et al., 2000) and plant growth (Dye et al., 2001). The contrast between upland and lowland evapotranspiration (ET) losses in a catchment may be particularly evident in semi-arid regions where ET in upland areas is often constrained by water availability during dry periods (Goodrich et al., 2000).

Riparian ecosystems are an important component of the lowland zone in catchments, and despite covering a small fraction of total catchment area, may have a significant effect on the delivery of water (Galatowitsch and Richardson, 2005). Since invasive exotic species tend to invade lowland and riparian locations, the Working for Water Programme has included these hydrologically sensitive zones in areas targeted for invasive clearing. Riparian and lowland areas in the Molenaars catchment constitute a significant proportion of the area designated for clearing by the Working for Water Programme. Given that vegetation in lowland areas may be expected to have a disproportionate effect on the catchment water balance, we hypothesised that the NDVI of this Working for Water area in the Molenaars catchment would be a better predictor of changes in annual river yield compared to the NDVI of the upland zone. While the Working for Water zone does include some mid-slope areas, it excludes most of the uplands and is referred to as the 'lowland zone' in this study.

\section{Methodology}

Because annual rainfall differences account for most of the inter-annual variations in river flow $(\mathrm{Q})$, annual river flow depth was normalised by annual rainfall totals $(\mathrm{P})$ to determine the river yield $(\mathrm{Q} / \mathrm{P})$. Annual river yield was regressed on the average NDVI for each year using a linear least square regression model, and the regression equation was tested for statistical significance. This procedure was repeated using the NDVI from both the lowland and upland zones.

River flow in the Molenaars catchment is measured at the DWAF gauging weir number $\mathrm{H} 1 \mathrm{H} 018$, located at latitude $33^{\circ} 43^{\prime \prime} 24^{\prime}$ S; longitude $19^{\circ} 10^{\prime \prime} 13^{\prime}$ E (Fig. 1). The catchment has a substrate of sandstone-granite mixtures (Prinsloo and Scott, 1999) and is characterised by steep slopes with elevations ranging from approximately $300 \mathrm{~m}$ to $2000 \mathrm{~m}$. Most of the $113 \mathrm{~km}^{2}$ catchment is undeveloped and covered by fynbos vegetation. Invasive tree species (Acacia, Hakea, Pinus) cover parts of the lowland and mid-slope areas and almost $30 \%$ of the catchment has been designated for invasive clearing by the Working for Water Programme (Fig. 1).

Daily river flow data were obtained from the DWAF using their on-line database www.dwaf.gov.za/hydrology and flow volumes were converted to flow depths $(\mathrm{mm})$. There are 13 rain gauges located within $20 \mathrm{~km}$ of the catchment but none were located inside the catchment perimeter. All the gauges were in 


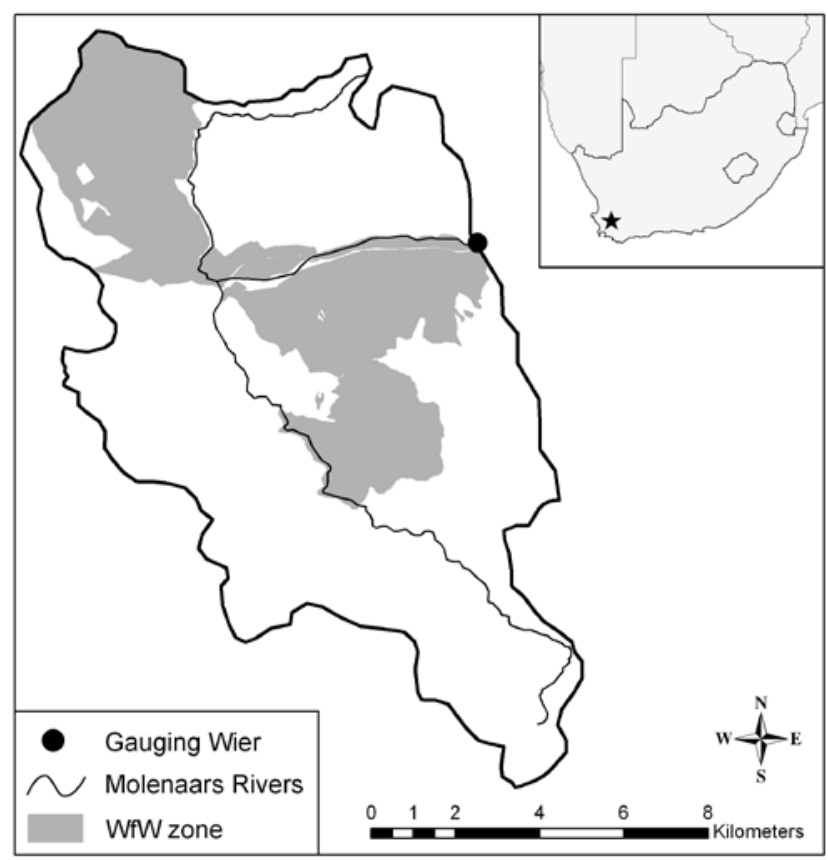

Figure 1

The Molenaars catchment with the Working for Water (WfW) designated zone for invasive clearing.

lowland areas intended for agricultural applications, and most had short or discontinuous records. Daily rainfall data from a gauge located at $33^{\circ} 38^{\prime \prime} 59^{\prime} \mathrm{S} 19^{\circ} 13^{\prime \prime} 59^{\prime} \mathrm{E}$ were chosen for use in the study based on the proximity of the gauge to the catchment and the record length. These data were available from 1960 to 1999 and were provided by the South African Agricultural Research Council, Institute for Soil Climate and Water (ARCISCW Gauge Number 20151). Data after 1999 were drawn from a one kilometre gridded rainfall data set compiled for the Western Cape region by the South African ARC-ISCW. Gridded values were based on interpolating data from all available rain gauges in the region (Malherbe, 2006). An examination of area-averaged annual rainfall totals for the catchment calculated using the gauge and gridded data sets prior to 1999 revealed very little difference between the two data sets. For this winter rainfall region, we designated April 1 to March 31 as the water year, and annual river flow depth and rainfall were cumulated over this period to derive river yield for each year.

The normalised difference vegetation index (NDVI) was used to quantify transpirationally active (green) vegetation from satellite spectral radiometric data and this index was calculated as:

$$
\mathrm{NDVI}=(\mathrm{NIR}-\mathrm{RED}) /(\mathrm{NIR}+\mathrm{RED})
$$

where:

NIR and RED are respectively the near infrared and red spectral reflectance.

Spectral radiometric data from the Advanced Very High Resolution Radiometer (AVHRR) instruments carried onboard the US National Oceanic and Atmospheric Administration (NOAA) polar-orbiting satellites were used to calculate daily NDVI values. These AVHRR data were obtained and processed by the South African ARC-ISCW for the period 1985-2003, excluding 1994 because of the failure of the AVHRR instrument onboard the
NOAA-13 satellite. The ARC-ISCW data processing included the reduction of daily observations to $10 \mathrm{~d}$ composited NDVI products at $1 \mathrm{~km}$ ground resolution using the maximum NDVI value method described by Holben (1986). Additional processing steps included geometric corrections and the application of a cloud mask. The NDVI compositing approach is intended to provide a consistent product which is insensitive to variations in atmospheric conditions and sun-target-sensor geometry (Holben, 1986). A full description of the AVHRR data processing is given by Wessels et al. (2004).

The annual average NDVI was calculated for each pixel in the Molenaars catchment using the $10 \mathrm{~d}$ composited NDVI values. It was evident during the initial processing of the NDVI data that shadows from the mountains in this catchment were causing major reductions in NDVI values in months when the solar elevation was low. Consequently, we calculated the average NDVI for each year using data from November 1 to March 31.

\section{Results}

The NDVI time-series for the upland and lowland zones in the Molenaars catchment followed broadly similar trends over the study period (Fig. 2). As expected, the lowland NDVI values were consistently larger than those of the upland zone. Plotting the lowland and upland annual NDVI values against each other revealed a strong systematic relationship in all but two years (Fig. 3). A linear least squares regression line was fitted to the data in Fig. 3, excluding the two outliers, resulting in a $\mathrm{R}^{2}$ of 0.938 , slope of 0.943 and intercept of 0.100 . The two points that were above the upper $95 \%$ prediction bound of this regression line were for 1998 and 1999. In both years, the differences between upland and lowland NDVI values were greater than would have been expected.

The larger than expected difference between upland and lowland NDVI in 1998 and 1999 was most likely due to differences in fire histories in the two zones. In 1998, $42.2 \%$ of the upland zone burnt compared to $9.4 \%$ of the lowland zone. While $21.4 \%$ of the lowland zone and $8.0 \%$ of the upland zone burnt in 1999, the cumulative area burnt in the upland zone over these two years was still substantially greater than that in the lowland zone (50.2\% compared to $30.8 \%$ ). Consequently, the upland NDVI was still less than expected compared to the NDVI of the lowland zone in 1999 (Fig. 3). The lower than normal rainfall

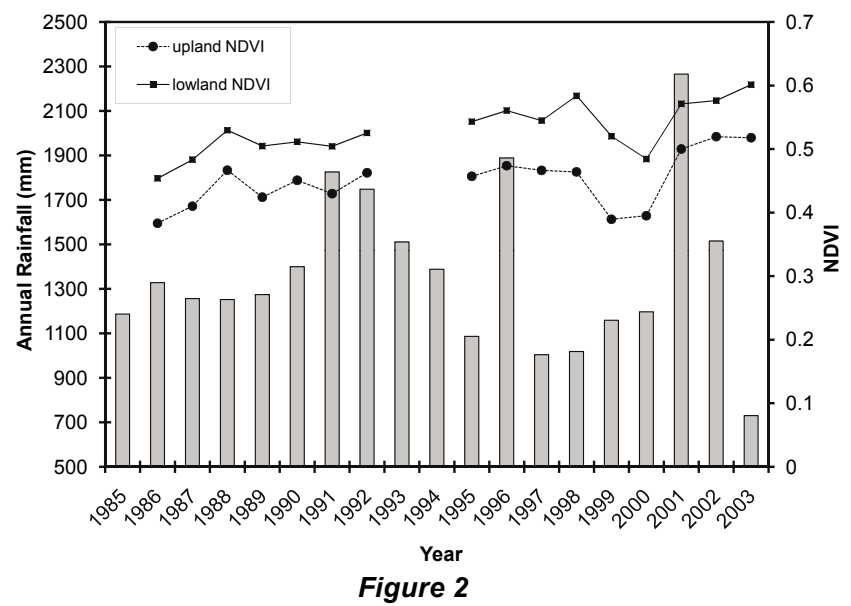

Average summer (November-March) NDVI time series for the upland and lowland areas of the Molenaars catchment and annual rainfall totals. NDVI data were incomplete for the 1993 and 1994 summers. 


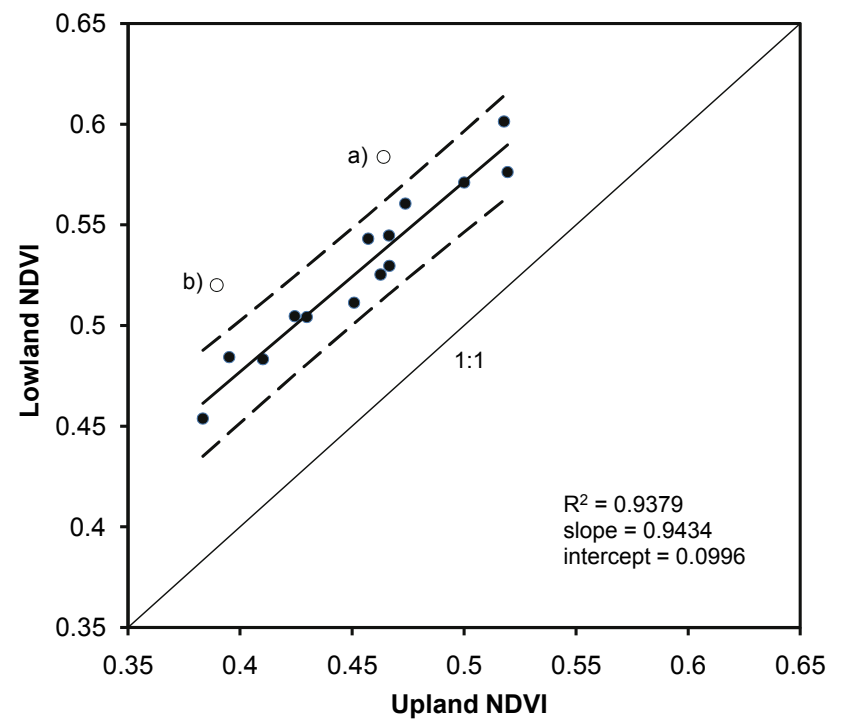

Figure 3

Relationship between lowland and upland average NDVI (November-March). The broken lines indicate $95 \%$ prediction bounds for the linear least squares regression line and open circles indicate the outliers associated with the data for a) 1998 and b) 1999 .

totals in 1998 and 1999 (Fig. 2) may have also enhanced differences in vegetation growth in the two zones. Despite below average rainfall in 1997, 1998 and 1999, redistribution of upland soil water to the lowland zone may have minimised the effects of the drought on plant growth in this zone.

The relationship between annual river yields and the lowland and upland NDVI are given in Fig. 4. The most notable features of the two plots in Fig. 4 were 1) river yields consistently exceeded $100 \%(\mathrm{Q}>\mathrm{P})$, and 2) there was an apparent negative relationship between river yield and NDVI with three clear outliers. Overestimation of river yield was most likely associated with underestimated catchment rainfall totals that were based on data from a single rain gauge. Large parts of the catchment are at substantially higher elevations (up to $2000 \mathrm{~m}$ ) than the rain gauge (elevation $=363 \mathrm{~m}$ ) and orographic effects were likely to generate substantially larger rainfall amounts in these high elevation areas than those measured at the gauge. Assuming that there was good systematic agreement between the true catchment rainfall and the rain gauge totals, the relationship between calculated river yield and lowland NDVI would be retained (with a systematic offset). This is a reasonable assumption given that the analyses are based on annual rainfall totals that tend to demonstrate more systematic spatial patterns than observations at shorter periods.

River yields associated with the three outliers in Figs. 4A and 4B (water years 2000, 2001 and 2002) were considerably smaller than those in any of the other 13 years. These reductions in river yields were most likely due to changes in hydrological process associated with severe drought. Each of the outlier years followed three-year drought periods when rainfall totals were substantially below average (Fig. 2). Despite well above average rainfall in 2001 and average rainfall in 2002 , the small river-flow response to rainfall may have been a consequence of continued recharge of depleted storages at the expense of river flow production. Bank and groundwater recharge may have been important mechanisms responsible for reduced river yields.
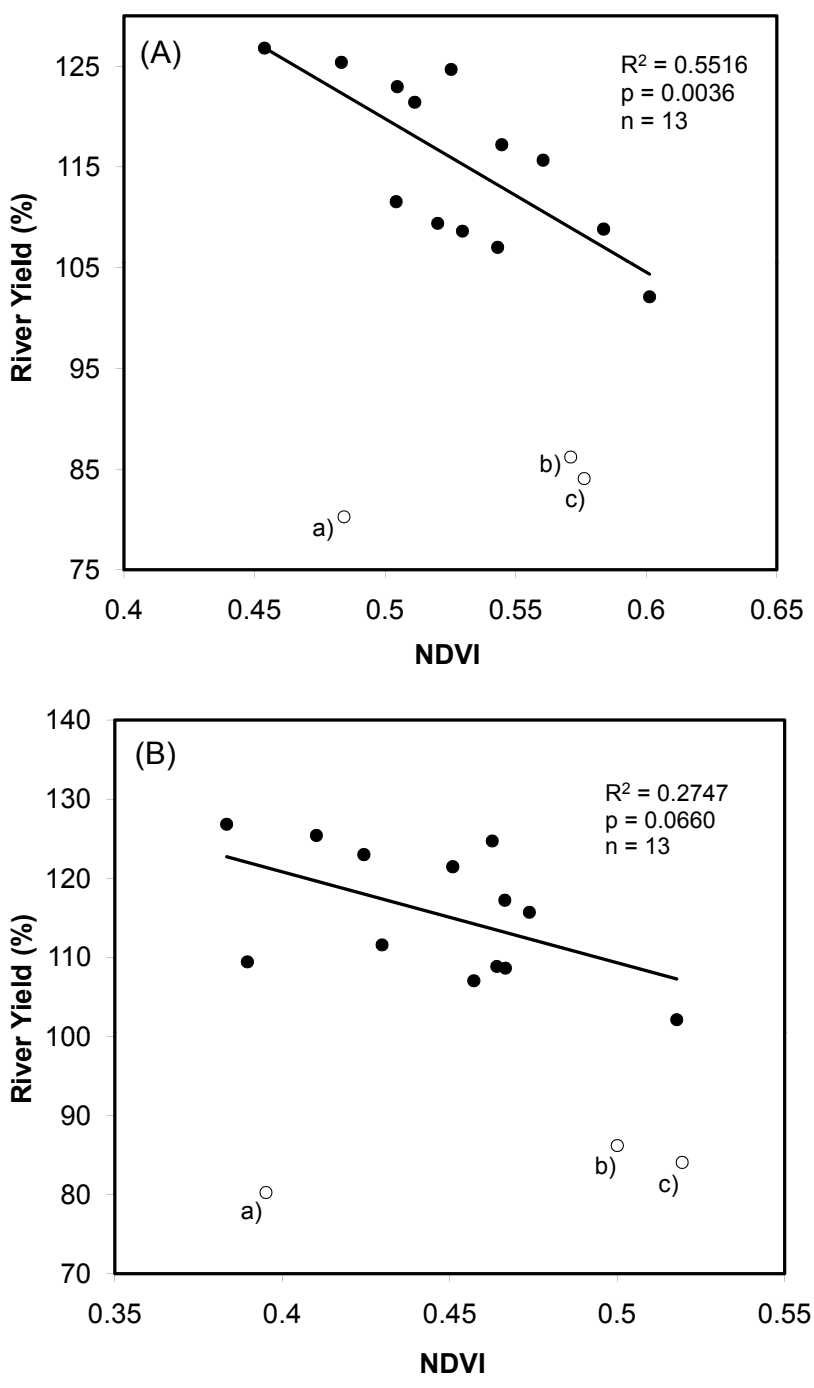

Figure 4

Relationship between annual river yield (\%) and the summer NDVI for A) the lowland zone and B) the upland zone.

Open circles indicate outliers associated with data for a) 2000, b) 2001, and c) 2002 .

When outliers for 2000, 2001 and 2002 were removed from the data set and river yield was regressed on the lowland and upland NDVI, lowland NDVI explained $55.2 \%$ of the variance in river yield $(\mathrm{p}=0.004)$ compared to $27.5 \%$ of the variance explained by the upland NDVI, a value that was not statistically significant $(p=0.066)$. When river yield was regressed on the average NDVI for the entire catchment, the variance explained was not significant $\left(\mathrm{R}^{2}=0.375 ; \mathrm{p}=0.206\right)$. These findings indicated that in years without substantial recharge of catchment storages, the amount of transpirationally active vegetation in the lowland region had a significant effect on river yield. This result is consistent with the observation made by authors such as Galatowitsch and Richardson (2005) and Huxman et al. (2005), that vegetation in lowland zones has a disproportionate effect on catchment water deliveries.

While the results of this investigation have demonstrated a significant relationship between annual river yield and the lowland NDVI, the interpretation of such relationships in terms of hydrological processes (e.g. greater transpiration with larger NDVI) should be made with caution. The NDVI may be a 
surrogate for other controlling variables, such as inter-annual variations in annual rainfall and soil water. Since there was no statistically significant relationship between NDVI and annual rainfall totals $\left(\mathrm{R}^{2}=0.001\right)$, it is unlikely that this was a spurious correlation with NDVI being a surrogate variable for rainfall. The observed reduction in river yield with increasing NDVI is consistent with the expected relationship between changes in LAI (NDVI) and water losses due to enhanced transpiration. If the NDVI was a surrogate for rainfall, then we would expect river yields to increase with larger NDVI values.

\section{Conclusions}

This study was designed to investigate the viability of relating annual river yields to remotely sensed changes in vegetation cover in a large mountainous fynbos catchment. Results from the Molenaars catchment indicated that a spectral vegetation index such as the NDVI may provide a basis for directly quantifying river yield response to changes in vegetation, but with a number of important caveats. First, lack of high-elevation rain gauges in the region and the underestimation of catchment area average rainfall totals preclude the quantification of actual changes in river yield due to changes in vegetation cover. While it may not be practical to install and maintain additional high-elevation gauges in the region, data from a temporary network would allow investigators to derive empirical relationships between rainfall amounts and elevation which could be used to adjust low-elevation rain-gauge data to be representative of catchment values. This is important for empirical studies such as the one presented here and for many other hydrological investigations and applications in the region.

The second important consideration in developing relationships between river yield and changes in catchment vegetation cover relates to the identification of hydrologically sensitive areas in a catchment. This study demonstrated that changes in the annual river yield in the Molenaars catchment were affected by variations in vegetation cover (NDVI) in the zone targeted for invasive clearing by the Working for Water Programme. No significant relationship existed between river yield and the NDVI of the upland portion of the catchment or NDVI of the entire catchment. Definition of the hydrologically sensitive or lowland zone is an important issue for future research and may be based on topography, soils and vegetation. The zone identified for invasive clearing by the Working for Water Programme was taken as the critical lowland zone in this study but also included some upland areas that had been invaded. A more significant relationship between river yield and the NDVI may have been achieved using a different segmentation of the catchment.

The relationship between river yield and lowland NDVI in the Molenaars catchment, and the existence of outliers associated with drought conditions points to the existence of critical thresholds affecting river yield. These thresholds are most likely associated with storage deficits in the catchment and decoupling of river yields from vegetation condition. Critical storage depletion and recharge thresholds may vary by catchment depending on characteristics such as catchment storage capacity and vegetation type. Identifying anomalous river yields relative to catchment NDVI may be valuable for refining process models that explicitly quantify these storages and how vegetation controls water fluxes.

The final consideration for extending this research pertains to the months chosen to characterise catchment vegetation cover using the NDVI. Shadows during months with low solar elevation are a significant concern for interpreting satellite spectral reflectance measurements in Western Cape mountain catchments. A systematic reduction in the NDVI time series that corresponds to decreasing solar elevation was found to be indicative of this contamination in the satellite data. The average NDVI from months that were considered to be largely free from the effects of shadows was used to predict river yields. It is implicit in this strategy that the vegetation condition in each month had an equal effect on processes affecting river yield. There may be periods within this window when vegetation cover is a more sensitive indicator of variations in evapotranspiration losses and river yield.

\section{Acknowledgements}

We extend our thanks to a number of people who provided valuable assistance with this study. Dawie van Zyl of the South African Agricultural Research Council, Institute for Soil Climate and Water processed the AVHRR satellite data. Assistance with data processing and analyses was provided by Ryan Bart, Dillon Fitch and Daniel Hawtree. This study was funded by the US National Aeronautics and Space Administration, Land Cover Land Use Change Program, Grant No. NNG05GR14G.

\section{References}

BOSCH JM, VAN WILGEN BW and BANDS DP (1986) A model for comparing water yield from fynbos catchments burnt at different intervals. Water SA 12 (4) 191-196.

DYE PJ and POULTER AG (1995) A field demonstration of the effect on streamflow of clearing invasive pine and wattle trees from a riparian zone. S. Afr. For. J. 173 27-30.

DYE P, MOSES G, VILAKAZI P, NDLELA R and ROYAPPEN M (2001) Comparative water use of wattle thickets and indigenous plant communities at riparian sites in the Western Cape and KwaZuluNatal. Water SA 27 (4) 529-538. http://www.wrc.org.za/archives, watersa\%20archive/2001/October/1396.pdd

GALATOWITSCH S and RICHARDSON DM (2005) Riparian scrub after clearing of invasive alien trees in headwater streams of the Western Cape, South Africa. Biol. Conserv. 122 509-521.

GOODRICH DC, SCOTT R, QI J, GOFF B, UNKRICH CL, MORAN MS, WILLIAMS D, SCHAEFFER S, SNYDER K, MACNISH R, MADDOCK T, POOL D, CHEHBOUNI A, COOPER DI, EICHINGER WE, SHUTTLEWORTH WJ, KERR Y, MARSETT R and NI W (2000) Seasonal estimates of riparian evapotranspiration using remote and in situ measurements. Agric. For. Meteorol. 105 281-309.

HOLBEN BN (1986) Characteristics of maximum-value composite images from temporal AVHRR data. Int. J. Remote Sens. 7 14171434.

HUXMAN TE, WILCOX BP, BRESHEARS DD, SCOTT RL, SNYDER KA, SMALL EE, HULTINE K, POCKMAN WT and JACKSON RB (2005) Ecohydrological implications of woody plant encroachment. Ecol. 86 (2) 308-319.

LE MAITRE DC, VAN WILGEN BW, CHAPMAN RA and McKELLY DH (1996) Invasive plants and water resources in the Western Cape Province, South Africa: modelling the consequences of a lack of management. J. Appl. Ecol. 33 161-172.

LE MAITRE DC, VERSFELD DB and CHAPMAN RA (2000) The impact of invading alien plants on surface water resources in South Africa: A preliminary assessment. Water SA 26 (3) 397-408. http:// www.wrc.org.za/archives/watersa\%20archive/2000/July/1220.pdf

MALHERBE J (2006) Personal communication. Agricultural Research Council - Institute for Soil, Climate and Water, Private Bag X79, Pretoria 0001, South Africa.

PRINSLOO FW and SCOTT DF (1999) Streamflow response to the clearing of alien invasive trees from riparian zones at three sites in the Western Cape Province. S. Afr. For. J. 185 1-7.

SCOTT DF (1999) Managing riparian zone vegetation to sustain streamflow: results of paired catchment experiments in South Africa. Can. J. For. Res. 29 (7) 1149-1157. 
SELLERS PJ (1985) Canopy reflectance, photosynthesis and transpiration. Int J. Remote Sens. 6 1335-1372.

SIRIWARDENA L, FINLAYSON BL and McMAHON TA (2006) The impacts of land use change on catchment hydrology in large catchments: The Comet River, Central Queensland, Australia. J. Hydrol. 326 199-214.

SZILAGYI J (2000) Can a vegetation index derived from remote sensing be indicative of areal transpiration? Ecol. Model. 127 65-79.
WESSELS KJ, PRINCE SD, FROST PE and VAN ZYL D (2004) Assessing the effects of human-induced land degradation in the former homelands of northern South Africa with a $1 \mathrm{~km}$ AVHRR NDVI time-series. Remote Sens. Environ. 91 47-67.

VAN WILGEN BW, LITTLE PR, CHAPMAN RA, GORGENS AHM, WILLEMS T and MARAIS C (1997) The sustainable development of water resources: History, financial costs, and benefits of alien plant control programmes. S. Afr. J. Sci. 93 404-411. 